argued on the special ground of the fitness of women for the practice of our profession. Woman's peculiar capabilities were dwelt upon, based on her female qualities, no allusion being made as to her cxpacity for acquiring scientific knowledge by a single debater. First of all, it may be remarked that woinen are quite equal to men in all the qualities necessary for a professional life, and this argument failing, their advocates do not object to the inconsistency of supporting their claims on their special sexual merits. 'The Bill based on so large principles was carried, is now endorsed by the Senate, and is attempted to be thrust on the University in spite of the vast majority of the medical graduates being opposed to it. There is, therefore, no contradiction in voting for the admission of women on the broad prin. ciples of equality and opposing oneself to such an arbitrary and limited measure as this. I vote for giving women a trial on general grounds, not believing in their fitness for the different professions which they wish to practise. The attempt is not made, and I am then asked to vote for their admission to our profession for reasons based on their especial aptitura for it. To this I object.

It is well known that the objections used by medical graduates are founded on physiological laws, whilst the advocates of women base their arguments on social and political lawsof liberty, equality, and justice. In holding this position they ignore the rights of nature, and are assuming that their laws are applicable as between men and women, which is the very question at issue. There seems to be an absolute blindness to the consequences of women entering the profession when we see their advocates urging upon those who are devoted to the principles of freedom to join with them in the effort to bring about a state of things which will necessitate the most olious and unbearable legislation. They will scatter natural laws to the winds and replace them by any number of artificial ones. Legislation will have to be carried on about questions of place, preferment, and sex, causing irritation, injustice, and rivalries to an infinitely greater extent than is said now to affect our infinitesimally small number of the community.

If the professions are thrown open, the law must be put in operation as to the advisability of medical women holding posts of trust, such as parish appointments, in which they will have to attend inquests, make post-mortem examinations on men, \&c., and require an occasional absence from office for maternal duties. The advocates of freedom could not of course feel these objections, but would insist on any woman being allowed to compete with man for such an appointment. If women are to practise at the Bar legal enactments will again be required, first of all as to whether she may rise to the Bench, and if so, it must follow that no married woman ean hope to snceed to this elevation. What heartburnings this will bring to the married childless woman who has been the favourite leader in court! I assume of course that no amount of sentimentality will allow the High Courts of Judicature to stand still whilst the judge goes home to be confined. As to the Church, the difficulties of women entering that will perhaps be not so great and need no efforts of legislation. There appears to be no natural impediment to a woman preaching or conducting a religious service, nor I apprehend to her being raised to the bench of bishops. There may perhaps be a difficulty unknown to me in the transmission of apostolic authority or influence through a female, unless the question has already been determined by the case of Pope Joan. At all events, it is clear that on the principle of the rights of all, independent of sex, the natural and instinctive laws which have hitherto regulated society are to be put aside and any number of petty legal enactments will have to be framed in their stead, at every step a woman takes forward in the exercise of her profession. To lead her on in the path of success and then arrest her because she is a woman, will be inconsequential and gross injustice. Yet it must inevitably be done. How any man of liberal tendencies, as most graduates of the University of London are supposed to be, can contemplate with equanimity the necessary result of the mixing of the sexes in professional rivalry, it is difficult to conceive. Parliament will be fully occupied in the most odious legislation. The only explanation I can offer for the remarkable phenomenon is that graduates in arts do not believe the statement of doctors, that women bear babies, or if they do know it they trust that by some new mode of training and culture (the philosophers say the zeitgeist) a new order of things may perhaps come about. In this view perhaps some agreement might be found between us all.

It might be thought, with such opinions as I have ex- pressed, that I hold my vote for the admission of women to the rights of the University upon the slenderest tenure. I confess to this, being aware that it is only by blinding one's eyes to the consequences and yielding to the force of an argument, false as I believe the premisses are, that I grant their request. I feel it quite possible that I have no right to grant this, and ought rather to know that the rule of equality between men and women does not apply when the facts of nature stare me in the face and give it the lie. It is a serious matter to as sist in an undertaking which may tend to shake the foundations of society, which now rest on instinctive laws of nature; to break down barriers which canse obstruction to an infinitesimally small number; to raise a number of others; to cause annoyances and irritations which society will not be able to bear. If the reader smiles at all this, and says it will and can never occur, then the answer is obvious. Why upset the whole machinery of colleges and universities for the sake of a few amaterur doctors, fancy lawyers, and job parsons? Surely the play is not worth the candle.

I know of no one who is more wedaed to Liberal principles than myself (my friends even call me a Radical), but 1 maintain that all social and human laws must have a basis in nature. I hold that "no favour and fair play" is not applicable as between man and woman, that the social laws apply only to the genus homo, which is made up of two beings whose characteristics supplement one another. The advocates of the rights of women assume that a large political doctrine can be used as between the sexes, which is the very point for discussion and fair argument. For my own part, I like freedom and equality, and hate repressive laws of any kind, and therefore, arguing on the largest political principles, I prefer the present system rather than one which will necessitate legislation of the most adious kind. When I speak of laws of nature I am fully aware that there is no analogy between them and laws of man's construction; the former cannot be broken, although we may come in collision with them to our own discomfiture.

In conclusion, I cannot forbear from expressing my feelings as to the sadness of the spectacle of graduates of a learned University throwing outsuggestions that low and sordid motives actuate the medical faculty in its opinion as to the unfitness of women for its profession. These graduates will not, or perhaps cannot, see the physiological arguments, but this does not compel them to judge others by their own narrowness. The kind of advocacy they have used has already borne its fruits in strengthening the phalanx of their opponents, and assisting in producing the well-marked majority of votes, as seen in the division of Tuesday.

Grosvenor-street, May 12, 1877. Your obedient servant,

\section{THE DENTAL REFORM ASSOCIATION.} To the Editor of THE LANCET.

Sir,-I am sure your readers in general must be heartily tired of the lengthy controversy carried on in your pages in regard to dental politics, and I should consider further intrusion unwarrantable were it not that Mr. Tomes brings against me serious but happily most unwarrantable charges. In the first place, I am accused of a change of opinion, in itself a small matter, were it not associated with the much graver insinuation of having received students' fees for carrying out principles I have latterly renounced, a charge which I am sure Mr. Tomes, on sober consideration, will regret having ever made.

From the earliest period I decided to adopt dental surgery as a profession to the present moment, I have never altered my opinion in regard to the desirability of every dentist being a fully qualified medical man, and my own course in regard to that opinion will prove my consistency. When the dental diploma was first established I regarded it, as I do now, as an admirable test for proving the technical knowledge of the possessor, and one most desirable to be obtained by all practising the specialty of dental surgery. These views I have, as facts can fully bear out, consistently urged on all occasions since I was elected a member of the staff of that special hospital to which Mr. Tomes refers, and of which I have now the honour to be senior medical officer; and I am happy to state that $I$ have in many instances been the means of inducing its students to obtain that to which I myself owe more than to anything else any success I may have attained to in my pro- 
fessional career-viz., the possession of the M.R.C.S. The hostile association, as $\mathrm{Mr}$. Tomes is pleased to call a body of which I am at present the treasurer, entertains in general my opinions as expressed.

In regard to a second charge-viz., Mr. Cartwright's, and my opposition to the Dental Reform Association, I can only ask your readers to inquire for themselves, if they care to do so, and they will find that its committee worked most harrioniously and unitedly until the first meeting of Mr. Tomes's attendance, and when he upset what had already been agreed to, necessitating the resignation of Mr. Cartwright and myself, also of Mr. Saunders and Mr. Gaine. The only other charge to which $I$ will refer is my objection to the registration of the special-i.e., dental diploma. Mr. Tomes must be fully aware I have never for one moment offered any such objection; on the contrary, I most fully uphold it, and all I have ever said or done will go to prove it. In conclusion, I am truly pained to be compelled in justice to myself to have to defend charges emanating from one from whom in times past I received the greatest kindness both as a friend and an instructor, and of whose scientific achievements $I$ should only be too proud to be the possessor.

\section{South-End, May 14th, 1877.$$
\text { I am, Sir, yours, \&c., }
$$

A. Coleman.

** We have also received letters on this question from Mr. S. Cartiright and Dr. J. Smith, of Edinburgh, the publication of which we are compelled to postpone until our next issue.-ED. L.

\section{IDIOTS IN WORKHOUSES.} To the Editor of THE LANCET.

SrR,-Your article on "Idiots in Workhouses" in THस LANCET of April 28th calls attention to a question of great and pressing interest. Special institutions are needed in which these cases should be trained, not only with respect to educational but also to industrial attainments, in order at least to make them contribute something towards their support. Experience bas shown that this object can be fulfilled. In a workhouse no provision exists for the carrying out of either of these objects. In the Metropolitan Asylum District special institutions have been provided for the education and subsequent training of idiots, which have fully realised the purposes for which they were erected, and it is desirable that this system should be extended throughout the country. During last summer a committee, appointed by the Charity Organisation Society, composed of statesmen, philanthropists, and medical men, engaged in the treatment of idiots and imbeciles, met several times to consider the best means of providing for the education and care of this class of cases. Their resolutions have been embodied in a report, which is to be presented to the president of the Local Government Board on the 17th inst. That report recommends that the provisions already made, and for some years past carried ont in London for the above object, should be extended throughout the country. When it is considered that there are in England upwards of 10,000 idiots and imbeciles under twenty years of age who require training, and upwards of 20,000 imbeciles above this age, who, from not being trained in early life, are to a great extent useless, it seems desirable that measures should be taken to remedy this defect without delay.

I am, Sir, your obedient servant

FLATCher Beach, M.B. Lond. May 7 th, 1877. Medical Superintendent Clapton Idiot Asylum.

\section{PARLIAMENTARY INTELLIGENCE.}

\section{HOUSE OF COMMONS. Wednesday, May 9 th.}

HOSPITALS FOR THE MERCANTILE MARINE.

Captain BeDFord Prm moved the second reading of a Bill which proposed to establish Hospitals for the Mercantile Marine, along with a system of compulsory medical inspection, supported by a contribution of 5 per cent. from the seamen's wages. It was supported by Mr. Wheelhouse, Mr. Whalley, Mr. Biggar, and Sir J. Wilmot, and opposed as im. practicable and oppres sive by Mr. Whitwell, Mr. Gorst, Mr. E. Smith, and Sir C. Adderley. On a division it was thrown out by 212 to 11 .

\section{Thursday, May 10th. NUISANCES.}

Mr. A. Mirts asked the President of the Local Government Board whether, having regard to the terms of the Pablic Health Act, 1875, section 91, it was necessary, when summary proceedings against a nuisance were taken, to show that the nuisance complained of was injurious to health.

Mr. Sclater-Booth.-By the 91st and following sections of the Pablic Health Act, 1875, a summary remedy is provided supplementarv to the proceedings against a nuisance which may be instituted at Common Law or in Equity, but although the disjunctive word "or" is used in the sectionviz., "a nuisance or injurious to health"- the Court have held that, looking to the whole scope of the Sanitary Acts, some injury to health must in all cases be proved. It was proposed by the hon. gentleman when the Pablic Health Act of 1875 was passing through Parliament to make the disjunctive proposition stronger by prefixing the word "either" to "nuisance," so that the sentence would bave run "either a nuisance or injurious to health," \&c.; but the highest legal authorities were of opinion that the same construction as before would, nevertheless, be adopted by the Courts. I am glad to say that the whole subject of noxious trades and vapours is now under the consideration of a Royal Commission, who will probably report within the present session of Parliament.

\section{6 bituarm.}

\section{WILLIAM COULSON, F.R.C.S.}

ON the 5th of May, the subject of this notice died, in his seventy-sixth year, at No. 1, Chester-terrace, Regent's-park, and on the 9 th his remains were borne to their resting-place in the cemetery at Kensal-green. Born at Penzance, Cornwall, in the year 1802, his early education was obtained at the grammar-school in that town, where he evinced, according to the testimony of one of his tutors, much ability, diligence, and attention in his studies. The instruction afforded at this school was almost purely classical; but, although only about fourteen years of age, young Coulson foresaw the desirability and importance of a knowledge of modern lan. guages. He therefore repaired to Brittany, where he reo mained long enough to acquire an intimate acquaintance with the French language and literature. On his return to his native town he was, according to the custom of that time, apprenticed to a surgeon, Mr. Berryman; but, so rapid was his progress, that some time before the expiration of his term of apprenticeship, he entered as a pupil at $\mathrm{Mr}$. Grainger's School of Anatomy in the Borough, and shortly afterwards attended the practice of St. Thomas's Hospital. It was during the time that he was acting as dresser to Mr. Tyrrell that Coulson attracted the notice of Mr. Wakley, who had just started THE LANCET, and who was at that time manfully struggling against the attempts made by many influential persons to prevent the publication in that journal of reports of lectures and of the notes of cases treated in the hospitals. Coulson at once began to report hospital cases in TuE LANCer, and was in a short time elected a member of the editorial staff. In 1824, having completed his anatomical studies in London, he migrated to Berlin, where, during a residence of two jears, he made the best use of the advantages and opportunities which the Prussian capital then afforded, and formed a friendship with many of the distinguished men who taught in her schools, such as Rudolphi, Rust, and others. On returning to London in 1826 he was admitted a Member of the Royal College of Surgeons, and soon afterwards took part with Tyrrell, Jones Quain, Lawrence, and Wardrop, in the formation of the Aldersgate School of Medicine. At this time, too, he was actively engaged on THE LANCET, having the entire charge of the foreign department, for which his long residence in different parts of the Continent and his 